Article

\title{
Spectral Index for Quantifying Leaf Area Index of Winter Wheat by Field Hyperspectral Measurements: A Case Study in Gifu Prefecture, Central Japan
}

\author{
Shinya Tanaka ${ }^{1, *}$, Kensuke Kawamura ${ }^{2}$, Masayasu Maki ${ }^{3}$, Yasunori Muramoto ${ }^{4}$, \\ Kazuaki Yoshida ${ }^{5}$ and Tsuyoshi Akiyama ${ }^{6}$
}

1 Department of Forest Management, Forestry and Forest Products Research Institute, 1 Matsunosato, Tsukuba, Ibaraki 305-8687, Japan

2 Graduate School for International Development and Cooperation, Hiroshima University, 1-5-1 Kagamiyama, Higashi-Hiroshima 739-8529, Japan; E-Mail: kamuken@hiroshima-u.ac.jp

3 Faculty of Engineering, Tohoku Institute of Technology, 35-1, YagiyamaKasumi-cho, Taihaku-ku, Sendai, Miyagi 982-8577, Japan; E-Mail: makimasa@tohtech.ac.jp

4 Gifu Prefectural Agricultural Technology Center, 729-1 Matamaru, Gifu 501-1152, Japan; E-Mail: muramoto-yasunori@pref.gifu.lg.jp

5 Gifu Region Agriculture and Forestry Office, 5-14-53 YabutaMinami, Gifu 500-8384, Japan; E-Mail: yoshida-kazuaki@pref.gifu.lg.jp

6 River Basin Research Center, Gifu University, 1-1 Yanagido, Gifu 501-1193, Japan; E-Mail: amx12438@mail2.accsnet.ne.jp

* Author to whom correspondence should be addressed; E-Mail: tanas@ffpri.affrc.go.jp; Tel.: +81-29-829-8314; Fax: +81-29-873-3799.

Academic Editors: Tao Cheng, Zhengwei Yang, Yoshio Inoue, Yan Zhu, Weixing Cao and Prasad S. Thenkabail

Received: 1 December 2014 / Accepted: 22 April 2015 / Published: 27 April 2015

\begin{abstract}
Timely and nondestructive monitoring of leaf area index (LAI) using remote sensing techniques is crucial for precise and efficient management of crops. In this paper, a new spectral index (SI) for estimating LAI of winter wheat (Triticum aestivum L.) is proposed on the basis of field hyperspectral measurements. A simple index based on the empirical relationships between LAIs and SIs of all available two-waveband combinations from hyperspectral data is developed by considering the difference between reflectance values at 760 and $739 \mathrm{~nm}\left(\mathrm{DSI}_{\mathrm{R} 760-\mathrm{R} 739}=\mathrm{R}_{760}-\mathrm{R}_{739}\right)$. Among published and newly developed SIs, DSIR760-R739 exhibited a significant and strong linear relationship with LAI
\end{abstract}


and showed outstanding performance in LAI assessments. The permissible bandwidths for broad-band DSIR760-R739 investigated using simulated reflectance were $5 \mathrm{~nm}$ for both 760 and $739 \mathrm{~nm}$ center wavelengths. The results indicate that the linear regression model based on the narrow-band and broad-band DSIR760-R739 is a simple but accurate method for timely and nondestructive monitoring of LAI.

Keywords: ground-based measurement; hyperspectral; LAI; sensitivity; site-specific crop management; winter wheat

\section{Introduction}

In remote sensing, among all canopy variables, leaf area index (LAI) is identified as a key biophysical parameter for crop growth diagnosis and pre-harvest grain yield prediction [1,2], as well as having a key role in terrestrial ecosystem processes [3]. The green LAI, defined as the one-sided green leaf area per unit horizontal ground area [4], is directly related to the growth status of crops [5] and largely influences the spectral reflectance of vegetation canopies. Thus, for site-specific crop management, it is crucial to be able to estimate LAI in a timely and nondestructive manner using remote sensing, since the site-specific crop management requires both high-quality crop production and the minimization of adverse environmental effects via better fertilizer management [2,6-8].

To date, empirical regression models based on the spectral indices (SIs) have been widely used for estimating LAI in crop fields because SI is a simpler, more convenient, and lesser restrictive approach than multivariate statistical techniques or radiative transfer model inversions [6,9-11]. For example, the normalized difference vegetation index (NDVI) [12] has been widely used in the assessment of above-ground biomass (AGB) and LAI [2]. The modified soil-adjusted vegetation index (MSAVI), optimized soil-adjusted vegetation index (OSAVI), and enhanced vegetation index (EVI) were developed to minimize the effects of varying background soil reflectance and atmospheric influences in measuring vegetation signal [13-16]. Gitelson [17] proposed the wide dynamic range vegetation index (WDRVI) to accurately assess crop biomass and LAI under conditions of moderate to high AGB. Recently, Viña et al. [10] found that chlorophyll indices (the red-edge chlorophyll index [CIred-edge] and the green chlorophyll index [CIgreen]), devised for chlorophyll assessment at the leaf scale [18], are more accurate for LAI assessments of maize and soybean crops than for the above-mentioned SIs. These SI-based studies have successfully predicted LAI at various spatial scales using commercially available digital cameras, field spectroradiometers, or airborne and satellite-borne sensors [8,11,19-24].

Winter wheat (Triticum aestivum L.) is one of the most important crops in Japan and has been planted in more than 212,600 ha [25]. At the canopy scale, previous research has reported that the LAI for wheat can be accurately estimated by field spectral measurements [20,26,27]. However, SI-based empirical regression models have often been growth-stage-specific or year-specific [9,21,28,29]. Therefore, quantitative assessments of LAI remain uncertain. For example, Haboudane et al. found useful SIs (e.g., the modified triangular vegetation index, MTVI2) for LAI predictions of wheat, corn, and soybean based on simulated data using radiative transfer models [20]. However, the response of MTVI2 of airborne hyperspectral data with respect to LAI were different at maturity and senescence growth stages compared 
with that at early and mid-growth stage for wheat because of the dominance of the heads of the wheat plants and the increase in yellow and dry leaves [20,30]. These results suggest that the use of datasets representing actual canopy characteristics is important for development of new SIs.

Previous research demonstrated the suitability of hyperspectral remote sensing for monitoring crop growth [31-33]. Particularly for LAI predictions, the saturation problem of NDVI under moderate to high LAI conditions has been extensively investigated by developing new SIs using hyperspectral data $[34,35]$. The advantage of hyperspectral data is that it can be used for exploring useful SIs via various waveband combinations. However, hyperspectral data are costly to collect. Therefore, investigating the impact of new SI bandwidths on predictive accuracy is important- from an economic standpoint- for designing sensors [36]. In addition, the large numbers of hyperspectral bands are redundant; selection of important bands for crop monitoring is key to maximizing the efficiency of spectral data use [33].

The aim of this study was to identify simple and accurate SIs for LAI assessment of winter wheat. We explored new SIs based on the empirical relationships between the LAIs and SIs of all available two-waveband combinations. This exploration was conducted using field datasets collected at several growth stages of winter wheat. Then, the predictive ability and sensitivity of the newly developed and existing SIs were evaluated. Finally, the impacts of new SI bandwidths were investigated using simulated reflectance.

\section{Materials}

\subsection{Experimental Site}

Field experiments were conducted during two growing seasons in 2006 and 2007 at two experimental dried paddy fields of typical size in the Gifu Prefectural Agricultural Technology Center (GPATC) in southern Gifu prefecture, Japan $\left(35^{\circ} 26.6^{\prime} \mathrm{N}, 136^{\circ} 42^{\prime} \mathrm{E}\right)$ (Figure 1). The mean annual temperature and annual precipitation at GPATC in 2004 were $17.7^{\circ} \mathrm{C}$ and $1903 \mathrm{~mm}$, respectively [37].
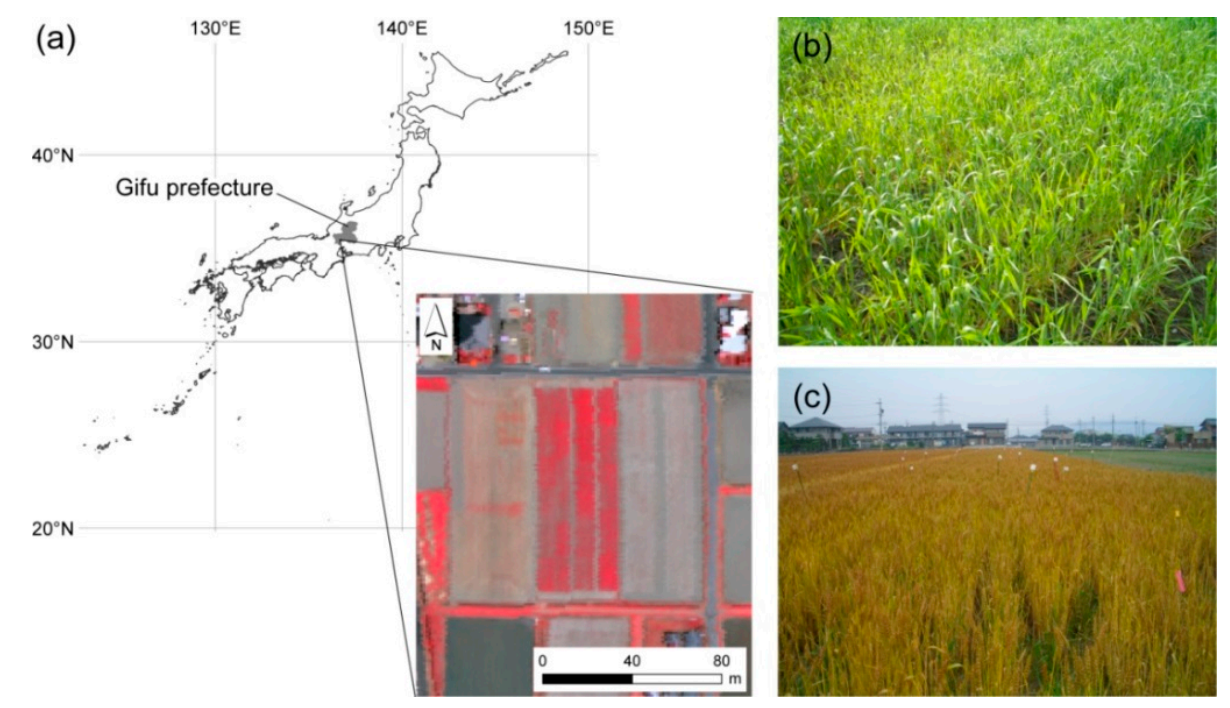

Figure 1. Location and photographs of the experimental site. (a) Location of the experimental site; (b) Photograph of the winter wheat on 25 April 2006 (just before heading); and (c) Photograph of the winter wheat on 2 June 2006 (10 days before harvest). 
Two major wheat cultivars (cv. "Norin 61" and "Iwainodaichi") were sown at a $30 \mathrm{~cm}$ ridge width at an $80 \mathrm{~kg} \cdot \mathrm{ha}^{-1}$ seeding rate (standard cultivation practice). We then investigated the "Norin 61" in 2006 and the "Norin 61" and "Iwainodachi" in 2007. The sowing and heading dates are summarized in Table 1. Wheat was harvested between late May and early June in both the 2006 and 2007 seasons. In this region, a rotational cropping system for rice, wheat, and soybean has been widely adopted, and accordingly, wheat was seeded in the experimental fields after the paddy rice had been harvested. Field measurements were performed in different dried paddy fields at GPATC in 2006 and 2007.

Table 1. Sowing and heading dates of winter wheat in the experimental field.

\begin{tabular}{cccc}
\hline Sowing Date/Heading Date & Norin 61 (2006) & Norin 61 (2007) & Iwainodaichi (2007) \\
\hline \multirow{3}{*}{ Sowing date } & & & 17 October 2006 \\
& & & 27 October 2006 \\
& 9 November 2005 & 7 November 2006 & 6 November 2006 \\
& & & 16 November 2006 \\
\hline Heading date & 29 April 2006 & 9 April 2007 & April 2007 \\
\hline \multicolumn{2}{c}{ Source: [38,39]. }
\end{tabular}

\subsection{Ground-Based Radiometric Measurements}

Canopy reflectance measurements were performed for 10:00-15:00 LST (GMT+9) under clear-sky conditions during the mid (stem extension growth stage) to late (1-2 weeks before harvest) growing stages (Table 2). The canopy spectra were measured using two portable hyperspectral spectroradiometers (ASD FieldSpec Handheld [FSHH] or FieldSpec 3 [FS3]; Analytical Spectral Devices, Boulder, CO, USA). The spectral range was 325-1075 nm for the FSHH and 350-2500 nm for the FS3. For all measurements, the sensor heads were positioned to look vertically downward, centered over the wheat hill, and were kept at a constant $1.3 \mathrm{~m}$ above the ground with a commercially available tripod. The radiometers had a $25^{\circ}$ field of view, for a viewing area of $58 \mathrm{~cm}$ in diameter at the canopy level.

Table 2. Overview of the field spectral measurements.

\begin{tabular}{rcccc}
\hline \multicolumn{1}{c}{ Date } & $\boldsymbol{n}$ & Measured Cultivar & Growth Stage & Spectroradiometer \\
\hline 4 Apr. 2006 & 15 & Norin 61 & Stem extension & FSHH \\
7 Apr. 2006 & 5 & Norin 61 & Stem extension & FSHH \\
17 Apr. 2006 & 15 & Norin 61 & Stem extension & FSHH \\
24 Apr. 2006 & 15 & Norin 61 & Stem extension & FSHH \\
21 May 2006 & 14 & Norin 61 & Maturing & FSHH \\
24 May 2006 & 6 & Norin 61 & Maturing & FSHH \\
10 Apr. 2007 & 9 & Norin 61 & Heading & FS3 \\
17 Apr. 2007 & 9 & Iwainodaichi & Anthesis & FSHH \\
26 Apr. 2007 & 6 & Norin 61 and Iwainodaichi & Grain filling & FSHH \\
\hline
\end{tabular}

Using the FSHH, we recorded the upwelling radiance of the wheat canopies, as well as that of the white Spectralon reflectance standard (Labsphere, Inc., North Sutton, NH, USA) at $\sim 15-30$ min intervals to determine the canopy reflectance. For the FS3 on 10 April 2007, the upwelling radiance of the white Spectralon reflectance standard was used to calibrate the instrument at 15-30 min intervals, 
and then the reflectance values of the wheat canopy were recorded. Finally, the spectral data stored in a personal computer were resampled at $1 \mathrm{~nm}$ intervals and exported as text files using computer software (RS2 for Windows; Analytical Spectral Devices, Boulder, CO, USA).

\subsection{Determination of Field LAI Value}

Agronomic survey was carried out on either the same day or the day following the hyperspectral measurements. Above-ground plant samples were obtained by cutting plants at the soil surface level in $50 \mathrm{~cm}$ lengths for one hill at each sampling point where the ground-spectral measurements had been made. All plant samples were transported to the laboratory immediately after sampling, where they were then divided into green leaves, yellow leaves, stems, and panicles. The surface area of all the green leaves was determined using a leaf area meter (LI-3100; Li-Cor Inc., Lincoln, NE, USA). The LAI values for a unit ground area were determined by multiplying with a conversion factor $(6.67$ for $50 \mathrm{~cm}$ length samples) in consideration of the ridge width of wheat.

\section{Methods}

\subsection{Contour-Map Approach for Exploring New Useful Spectral Indices}

Previous studies used contour maps of the coefficient of determination $\left(R^{2}\right)$ obtained by a linear regression analysis between agronomic variables and all possible two-waveband combinations of reflectance values to explore useful SIs [6,26,37,40-43]. This procedure is inadequate when the relationship between the LAI and the SI is nonlinear, and it cannot run with nonlinear fitting because of the requirement for initial parameter values [26]. Conversely, this contour-map approach has the advantage of providing an efficient selection of the optimal combination and width for use in existing sensors and for designing future sensors [6,41], and its results can easily be compared with those from other studies. Therefore, we used this approach with formulae that take the difference (Difference Spectral Index; DSI), ratio (Ratio Spectral Index; RSI), and normalized difference (Normalized Difference Spectral Index; NDSI) of the reflectance values to generate new useful SIs for predicting the LAI. In this analysis, spectral ranges of $<400 \mathrm{~nm}$ and $>1000 \mathrm{~nm}$ were omitted due to noise. The DSI, RSI, and NDSI are defined as follows:

$$
\begin{gathered}
\mathrm{DSI}_{\mathrm{R}_{i}-\mathrm{R}_{j}}=\mathrm{R}_{i}-\mathrm{R}_{j} \\
\mathrm{RSI}_{\mathrm{R}_{i}-\mathrm{R}_{j}}=\mathrm{R}_{i} / \mathrm{R}_{i} \\
\mathrm{NDSI}_{\mathrm{R}_{i}-\mathrm{R}_{j}}=\left(\mathrm{R}_{i}-\mathrm{R}_{j}\right) /\left(\mathrm{R}_{i}+\mathrm{R}_{j}\right)
\end{gathered}
$$

where $\mathrm{R}_{i}$ and $\mathrm{R}_{j}$ are the reflectance values at $i$ and $j \mathrm{~nm}$. In this study, both the $R^{2}$ value (highest- $R^{2}$ criteria) and the root mean square error (RMSE) (minimum-RMSE criteria) from the leave-one-out cross-validation (LOOCV) procedure were used to explore useful SIs. The RMSE was calculated by the following formula:

$$
\mathrm{RMSE}=\sqrt{\frac{1}{n} \sum_{i=1}^{n}\left(y_{i}-\hat{\mathrm{y}}_{i}\right)^{2}}
$$

where $y_{i}$ and $\hat{y}_{i}$ are the observed and predicted value of sample data $i$, respectively, and $n$ is the number of sample data. To compare the predictive ability of these three new SIs, we selected nine other major 
and potentially useful SIs for LAI prediction: NDVI, EVI, OSAVI, WDRVI, CIred-edge, CIgreen, MSAVI, MTVI1 and MTVI2 (Table 3).

Table 3. Existing spectral indices (SIs) used for comparison with the DSI, RSI, and NDSI.

\begin{tabular}{clc}
\hline Spectral Index & \multicolumn{1}{c}{ Formulation } & Reference \\
\hline NDVI & $\left(\mathrm{R}_{800}-\mathrm{R}_{670}\right) /\left(\mathrm{R}_{800}+\mathrm{R}_{670}\right)$ & {$[12,20]$} \\
EVI & $2.5\left[\left(\mathrm{R}_{800}-\mathrm{R}_{670}\right) /\left(\mathrm{R}_{800}+6 \mathrm{R}_{670}-7.5 \mathrm{R}_{445}\right)\right]$ & {$[14]$} \\
OSAVI & $\left(\mathrm{R}_{800}-\mathrm{R}_{670}\right) /\left(\mathrm{R}_{800}+\mathrm{R}_{670}+0.16\right)$ & {$[16]$} \\
WDRVI $(\alpha=0.1)$ & $\left(\alpha \mathrm{R}_{800}-\mathrm{R}_{670}\right) /\left(\alpha \mathrm{R}_{800}+\mathrm{R}_{670}\right)$ & {$[17]$} \\
CI $_{\text {red-edge }}$ & $\mathrm{R}_{800} / \mathrm{R}_{710}-1$ & {$[10,18,44]$} \\
CI $_{\text {green }}$ & $\mathrm{R}_{800} / \mathrm{R}_{550}-1$ & {$[10,18]$} \\
MSAVI & $0.5\left[2 \mathrm{R}_{800}+1-\sqrt{\left(2 \mathrm{R}_{800}+1\right)^{2}-8\left(\mathrm{R}_{800}-\mathrm{R}_{670}\right)}\right]$ & {$[15,20]$} \\
MTVI1 & $1.2\left[1.2\left(\mathrm{R}_{800}-\mathrm{R}_{550}\right)-2.5\left(\mathrm{R}_{670}-\mathrm{R}_{550}\right)\right]$ & {$[20]$} \\
& $1.5\left[1.2\left(\mathrm{R}_{800}-\mathrm{R}_{550}\right)-2.5\left(\mathrm{R}_{670}-\mathrm{R}_{550}\right)\right]$ & {$[20]$} \\
MTVI2 & $\sqrt{\left(2 \mathrm{R}_{800}+1\right)^{2}-\left(6 \mathrm{R}_{800}-5 \sqrt{\mathrm{R}_{670}}\right)-0.5}$ & \\
\hline
\end{tabular}

\subsection{Model Construction and Validation}

For each SI, linear and non-linear regression models between SI and LAI were constructed [10], and the two models were compared with the Akaike Information Criterion (AIC; [45]) to select the better model.

Then, a bootstrap procedure similar to that in previous studies $[46,47]$ was performed to evaluate the predictive ability of the SIs. First, the data were divided into a calibration dataset $(66.7 \%)$ and a validation dataset $(33.3 \%$ ) by stratified random sampling (four stratums; $0 \leq \mathrm{LAI}<1,1 \leq \mathrm{LAI}<2$, $2 \leq \mathrm{LAI}<3$, and LAI $\geq 3$ ) because there was less data in the high LAI range. Next, the linear or nonlinear model for each SI was fitted to the calibration dataset, and a set of best-fitted values was determined. Finally, the validation dataset was bootstrapped 1000 times, and for each repetition, the inverted linear or nonlinear model with the best-fitted parameters for each SI was used to predict LAI for the validation subsamples. In this study, same calibration dataset and bootstrapped samples in all SIs were used. To assess the predictive accuracy, the RMSE was used.

For our sensitivity analysis, the noise equivalent (NE) $\Delta$ LAI [10,48] was used to represent the sensitivity of the SI in detecting changes in LAI:

$$
\mathrm{NE} \Delta \mathrm{LAI}=\mathrm{RMSE}(\mathrm{SI} v s . \mathrm{LAI}) /[\mathrm{d}(\mathrm{SI}) / \mathrm{d}(\mathrm{LAI})]
$$

where $d(\mathrm{SI}) / \mathrm{d}(\mathrm{LAI})$ is the first derivative of the SI with respect to LAI, and the RMSE(SI vs. LAI) is the RMSE of the SI versus LAI relationship. The NEALAI has the advantage of allowing a direct comparison of different SIs [49].

All data handling and statistical analyses were performed using the R software (version 2.15.0) [50] and the nonlinear fitting was made using the "nls" function in R. 


\subsection{Determination of Bandwidths for Broad-Band SI}

To investigate the performance of new SI under different bandwidths (full width at half maximum; FWHM), simulated reflectance $\left(\mathrm{R}_{\text {sim }}\right)$ was used. In accordance with a previous study [36], the $\mathrm{R}_{\text {sim }}$ was simulated by Equation (6) with the Gaussian response function (Equation (7)):

$$
\begin{gathered}
\mathrm{R}_{\text {sim }}=\frac{\sum_{\lambda_{s}}^{\lambda_{e}} \mathrm{R}_{\lambda} f(\lambda, \sigma)}{\sum_{\lambda_{s}}^{\lambda_{e}} f(\lambda, \sigma)} \\
f(\lambda, \sigma)=\exp \left(-\frac{\left(\lambda-\lambda_{c}\right)^{2}}{2 \sigma^{2}}\right)
\end{gathered}
$$

where $\lambda$ is wavelength in the range of spectral response for simulated bandwidth, $\lambda_{c}$ is the central wavelength, and $\sigma=\frac{\text { FWHM }}{2 \sqrt{2 \ln 2}}$. Different bandwidths in the range of $1-61 \mathrm{~nm}$ were simulated to investigate changes in predictive accuracy using the RMSE values calculated by the bootstrap procedure described in the previous section. The bandwidths for which the RMSE was not greater than $5 \%$ of the smallest RMSE value (optimal ${ }_{1.05}$ criterion; e.g., [51]) were adopted as the permissible bandwidths for economical sensor design [36].

\section{Results}

\subsection{Agronomic Data}

Summary statistics of the field LAI values are shown in Table 4. The ranges of LAI in the entire dataset were $0.3-5.5$. These ranges were sufficiently broad to evaluate the predictive ability of the SIs. Conversely, the ranges of LAI in each dataset, i.e., dataset of the cv. "Norin 61" in 2006 and 2007 and the cv. "Iwainodaichi" in 2007, were insufficient for analysis by year or cultivar. In addition, the 2007 data was collected mainly at the specific growth stage (Table 2). For these reasons, all the data were pooled and then used for statistical analysis.

Table 4. Summary statistics of the field LAI values.

\begin{tabular}{cccccc}
\hline Variable & Statistic & Entire Dataset & Norin 61 (2006) & Norin 61 (2007) & Iwainodaichi (2007) \\
\hline \multirow{2}{*}{ LAI } & Average & 1.7 & 1.4 & 2.7 & 2.3 \\
& Max & 5.5 & 3.0 & 5.5 & 3.9 \\
& Min & 0.3 & 0.3 & 1.4 & 0.7 \\
& Range & 5.2 & 2.7 & 4.1 & 3.1 \\
$n$ & & 94 & 70 & 12 & 12 \\
\hline
\end{tabular}

\subsection{Contour Maps of $R^{2}$ Value}

Figure 2 shows contour maps of the $R^{2}$ values from the linear regression analysis between LAI and all possible two-waveband combinations of DSI, RSI, and NDSI, respectively. Similar results were also obtained in the RMSE values (data not shown). In DSI (Figure 2a), a higher $R^{2}(>0.75)$ and smaller RMSE $(<0.45)$ areas were found at the combination of red-edge wavelengths $(720-750 \mathrm{~nm})$ and rededge to NIR wavelengths $(740-840 \mathrm{~nm})$. The maximum $R^{2}$ value $(0.860 ; p<0.001)$ and minimum RMSE value (0.345) were obtained by the difference of the reflectance values at $760 \mathrm{~nm}$ and $739 \mathrm{~nm}$, 
i.e., DSIR760-R739. In RSI (Figure 2b), major $R^{2}>0.75$ areas with RMSE $<0.45$ included a combination of those around $500 \mathrm{~nm}$ and 760 or $990 \mathrm{~nm}$ wavelengths, $680 \mathrm{~nm}$ with red-edge to NIR wavelengths (735-930 nm, 960-1000 nm), and 730-760 nm wavelengths. The maximum $R^{2}$ value $(0.785 ; p<0.001)$ and minimum RMSE value (0.428) were obtained by RSIR760-R730. In NDSI (Figure 2c), a major $R^{2}>0.75$ area with RMSE $<0.45$ was found in region with a combination of around $760 \mathrm{~nm}$ and $730 \mathrm{~nm}$ wavelengths. The maximum $R^{2}(0.788 ; p<0.001)$ and minimum RMSE $(0.425)$ values were obtained by NDSIR760-R730.
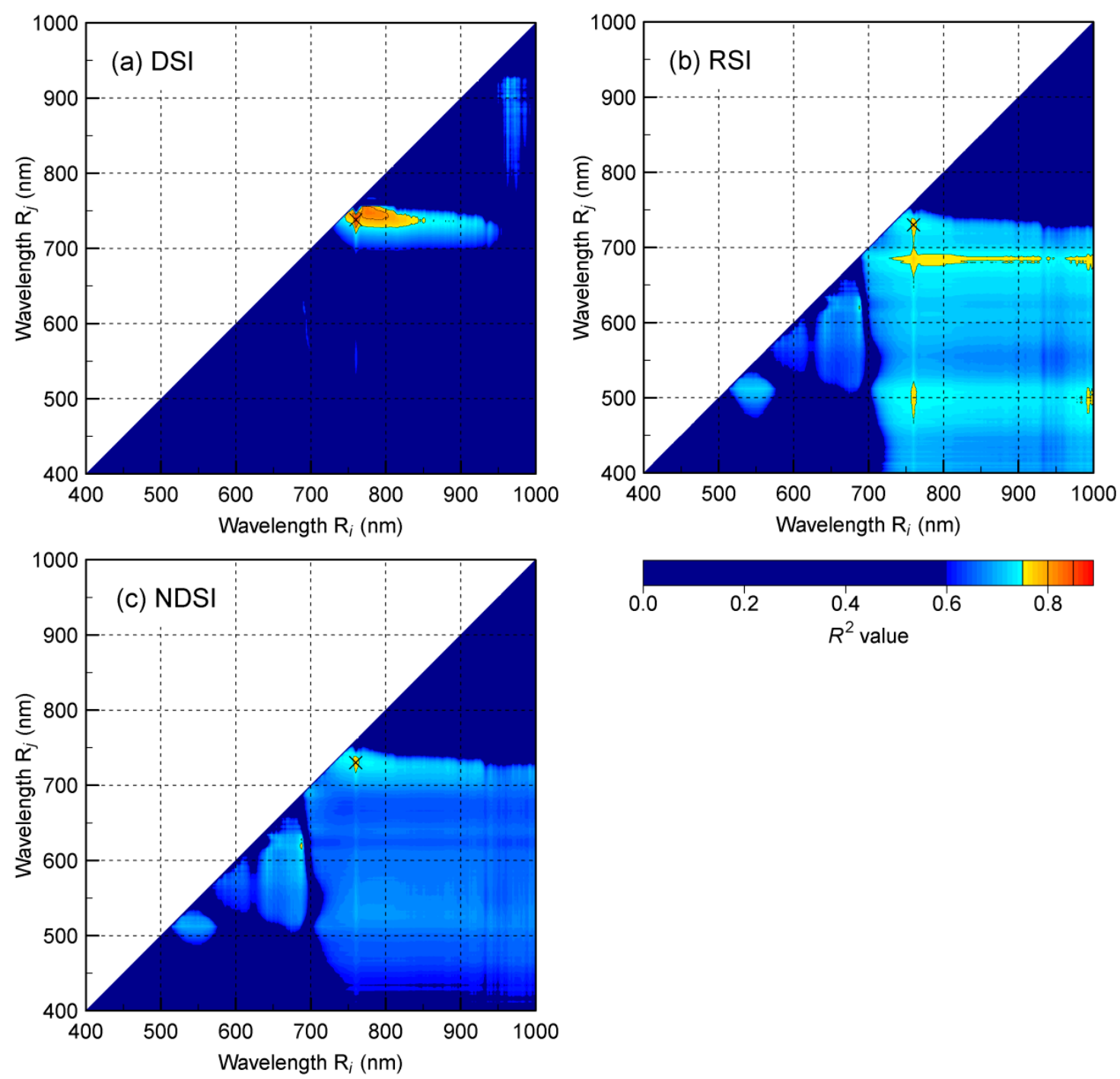

Figure 2. Contour maps of the coefficient of determination $\left(R^{2}\right)$ between LAI and (a) DSI; (b) RSI; and (c) NDSI. The crosses (x) indicate the points with the highest $R^{2}$ values.

Among the three contour maps, RSI showed $R^{2}>0.70$ in a larger number of combinations than the other SIs for estimating LAI. However, we obtained no $R^{2}>0.80$ with RSI. Overall, the DSIR760-R739 yielded the best $R^{2}$ values with respect to LAI $\left(R^{2}=0.860\right)$. Moreover, the best waveband-combination for DSI, RSI, and NDSI that were determined by the minimum-RMSE criteria were coincident with the results of the highest- $R^{2}$ criteria. These results indicate that these three new SIs are useful for LAI prediction; therefore, were further used in this study. 


\subsection{LAI Prediction and Validation}

Figure 3 shows the relationships between LAIs and SIs. NDVI, EVI, OSAVI, MSAVI and MTVI1 each exhibited an asymptotic relationship with LAI. In contrast, the other SIs (i.e., WDRVI, CIred-edge, CIgreen, MTVI2, DSIR760-R739, RSIR760-R730, and NDSIR760-R730) showed a more linear relationship with LAI. In particular, DSIR760-R739 had the most linear relationship with LAI. Based on the AIC, nonlinear model was selected for all SIs except for DSIR760-R739.
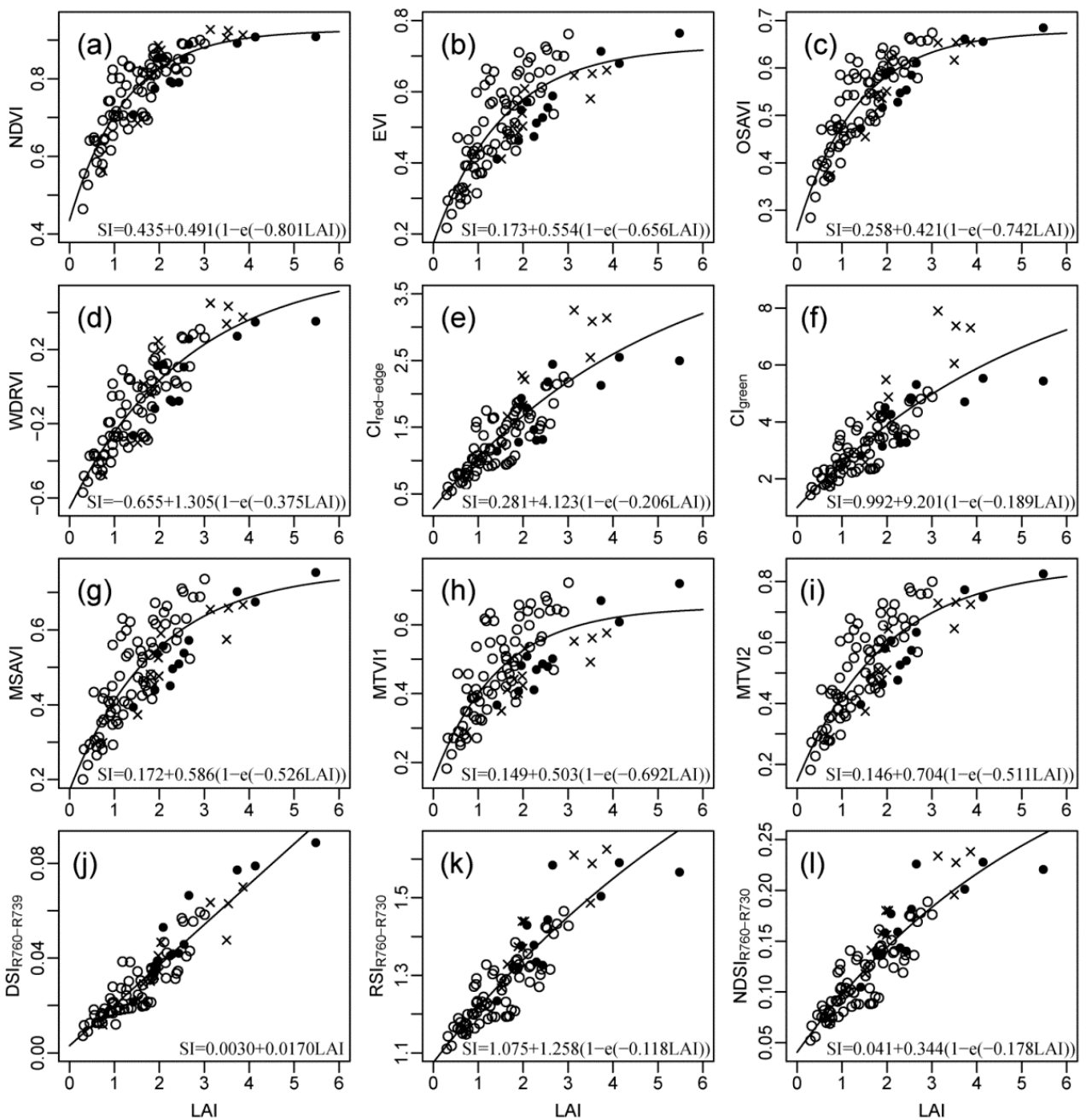

Figure 3. Relationships between LAI and (a) NDVI, (b) EVI, (c) OSAVI, (d) WDRVI, (e) CIred-edge, (f) CIgreen, (g) MSAVI, (h) MTV1, (i) MTV2, (j) DSIR760-R739, (k) RSIR760-R730, and (l) NDSI $760-R 730$. Open circles, filled circles, and crosses indicate data from the cv. "Norin 61" in 2006, cv. "Norin 61" in 2007, and cv. "Iwainodaichi" for 2007, respectively. Solid lines indicate the best-fitted lines.

Subsequently, we compared the predictive ability of SIs for assessing LAI by RMSEs obtained via the modified bootstrap procedure. Table 5 shows the point-estimated mean values of RMSE and the 95\% confidence intervals $(95 \% \mathrm{CI})$. Lower RMSE values $(\mathrm{RMSE} \leq 0.457)$ were obtained from the three newly explored SIs (DSIR760-R739, RSIR760-R730, and NDSIR760-R730) than those from previously known SIs (RMSE > 0.457). The linear predictive model based on DSIR760-R739 showed the best performance $(\mathrm{RMSE}=0.372 ; 0.280-0.487,95 \% \mathrm{CI})$. 
Table 5. Best-fitted parameters, point-estimated mean values of RMSE, and 95\% confidence intervals (CIs) of RMSE for narrow-band and broad-band SIs calculated by a modified bootstrap procedure.

\begin{tabular}{|c|c|c|c|c|c|c|}
\hline \multirow{2}{*}{ Spectral index } & \multirow{2}{*}{ Model $^{\text {a }}$} & \multicolumn{3}{|c|}{ Best Fitted Parameter } & \multirow{2}{*}{ RMSE } & \multirow{2}{*}{$95 \%$ CI } \\
\hline & & $Y_{0}$ & $a$ & $b$ & & \\
\hline NDVI & nonlinear & 0.431 & 0.499 & 0.811 & 0.466 & $0.357-0.546$ \\
\hline EVI & nonlinear & 0.183 & 0.589 & 0.574 & 0.656 & $0.535-0.847$ \\
\hline OSAVI & nonlinear & 0.263 & 0.434 & 0.691 & 0.492 & $0.404-0.617$ \\
\hline WDRVI & nonlinear & -0.674 & 1.300 & 0.409 & 0.487 & $0.378-0.566$ \\
\hline $\mathrm{CI}_{\text {red-edge }}$ & nonlinear & 0.242 & 3.770 & 0.252 & 0.516 & $0.404-0.605$ \\
\hline $\mathrm{CI}_{\text {green }}$ & nonlinear & 0.933 & 8.493 & 0.225 & 0.572 & $0.442-0.692$ \\
\hline MSAVI & nonlinear & 0.174 & 0.633 & 0.475 & 0.582 & $0.469-0.753$ \\
\hline MTVI1 & nonlinear & 0.165 & 0.545 & 0.555 & 0.824 & $0.622-1.046$ \\
\hline MTVI2 & nonlinear & 0.144 & 0.753 & 0.474 & 0.541 & $0.434-0.687$ \\
\hline $\mathrm{DSI}_{\mathrm{R} 760-\mathrm{R} 739}$ & linear & 0.003 & 0.017 & NA & 0.372 & $0.280-0.487$ \\
\hline $\mathrm{RSI}_{\mathrm{R} 760-\mathrm{R} 730}$ & nonlinear & 1.071 & 0.994 & 0.165 & 0.457 & $0.371-0.551$ \\
\hline $\mathrm{NDSI}_{\mathrm{R} 760-\mathrm{R} 730}$ & nonlinear & 0.039 & 0.300 & 0.224 & 0.455 & $0.368-0.553$ \\
\hline Broad-band DSI ${ }_{\mathrm{R} 760-\mathrm{R} 739}$ & linear & 0.006 & 0.017 & NA & 0.390 & $0.302-0.477$ \\
\hline
\end{tabular}

a Inverted regression model, LAI $=\frac{\ln \left(1 /\left(1-\frac{S I-Y_{0}}{a}\right)\right)}{b}$, was used for nonlinear models, while the model, $\mathrm{LAI}=\frac{\mathrm{SI}-Y_{0}}{a}$, was used for the linear model in the LAI prediction.

On the basis of the sensitivity analysis, we found large differences in sensitivity when LAI value exceeded 3.0 but only minor differences among SIs when LAI values were below 3.0 (Figure 4).

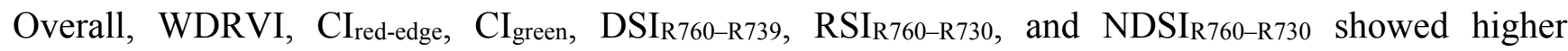
sensitivities with respect to LAI at moderate to high LAI values (3.0-5.5). DSIR760-R739, in particular, revealed the highest sensitivity when LAI exceeded 1.5, indicating that it is effective in predicting high LAI values.

On the basis of its high predictive ability, high sensitivity, and high degree of linearity, we consider DSIR760-R739 to be the most useful SI for estimating LAI in our dataset.

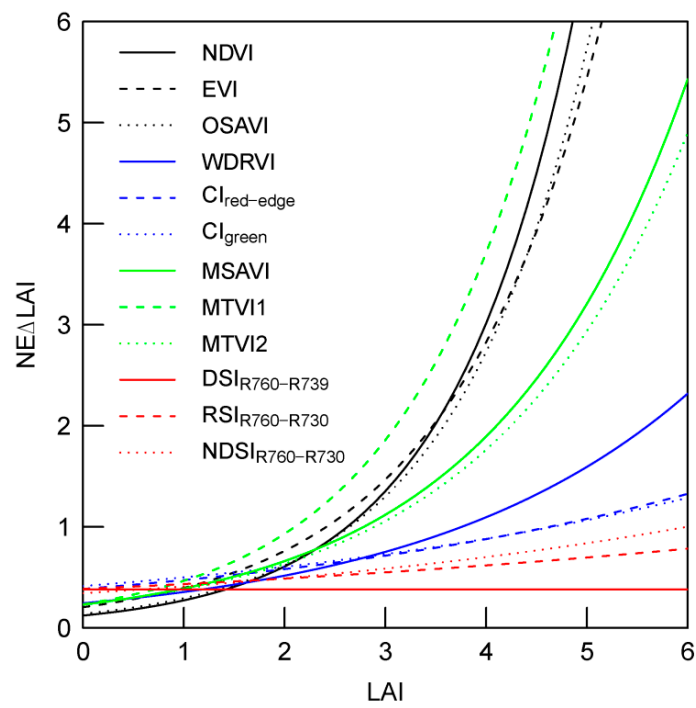

Figure 4. Sensitivity (NEALAI) of the SIs tested in the study. 


\subsection{Impact of Bandwidths on Predictive Accuracy}

The impact of bandwidths on predictive accuracy was investigated using DSIR760-R739 with simulated reflectance $R_{\text {sim. }}$ A best predictive accuracy was found to be the narrow-band DSIR760-R739 (i.e., bandwidths are $1 \mathrm{~nm}$ for 760 and $739 \mathrm{~nm}$ center wavelengths). The predictive accuracy decreased with increases in bandwidths, as shown in Figure 5. The downward trends of predictive accuracy were different in 760 and $739 \mathrm{~nm}$ center wavelengths. When the bandwidth at the $760 \mathrm{~nm}$ center wavelength was as narrow as $9 \mathrm{~nm}$, the impact of increases in bandwidths was relatively small for the $739 \mathrm{~nm}$ center wavelength. Although increases in bandwidths decreased predictive accuracy, the broad-band DSIR760-R739 (e.g., $15 \mathrm{~nm}$ for both wavelengths) had higher predictive accuracy (i.e., RMSE < 0.455) than the existing SIs listed in Table 5. The permissible bandwidths determined by the optimal 1.05 criterion were found to be $5 \mathrm{~nm}$ for 760 and $739 \mathrm{~nm}$ center wavelengths (Table 5).

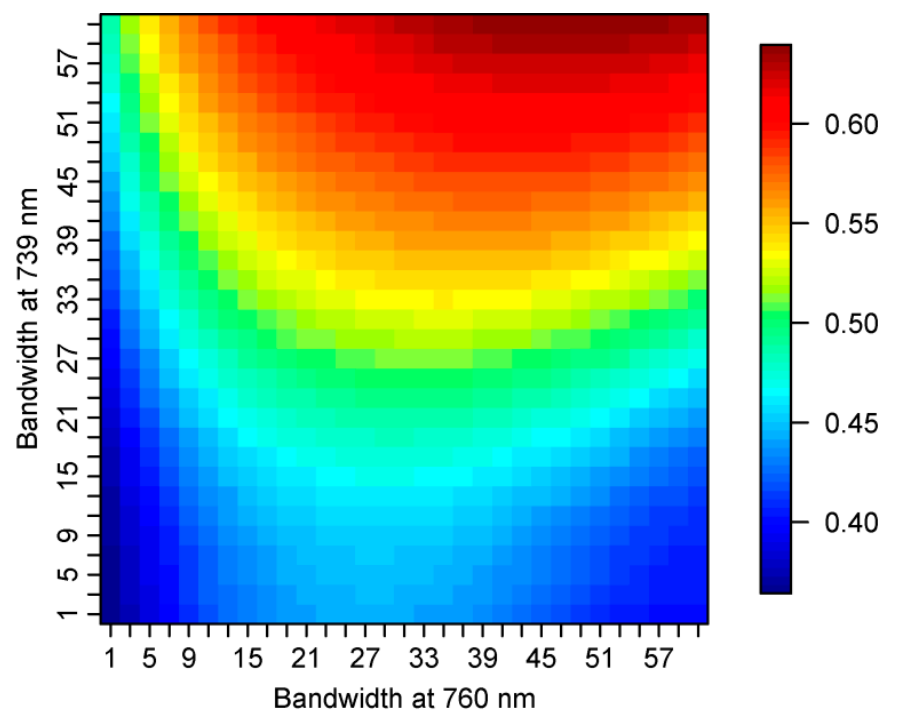

Figure 5. Contour map of RMSE value estimated from predictive model under different bandwidths (1-61 nm) based on the DSIR760-R739.

\section{Discussion}

Using the contour map approach, three SIs (DSIR760-R739, RSIR760-R730, and NDSIR760-R730) were found to be closely related to LAI (Figure 2). In particular, DSIR760-R739 was most significantly related to LAI $\left(R^{2}=0.860\right.$; RMSE $\left.=0.345\right)$. As shown in Figure 2, the wavelengths between 730 and $760 \mathrm{~nm}$ showed the most important spectral signatures for LAI assessment. The red-edge-NIR wavelengths are recognized as the most important spectral signatures for the assessment of LAI and canopy chlorophyll content [52-55]. In general, because of the multiple scattering of light in canopies, the reflectance values of the NIR wavelengths increase as LAI increases [56,57]. First-derivative processing is well known to be effective for enhancing the spectral signature from a target by removing noise. Difference processing of two close wavelengths yields results similar to those of the first-derivative processing. Therefore, we considered the spectral signature of the NIR wavelengths, which are sensitive to changes in LAI, to be enhanced by difference processing. As the canopy reflectance values of red-edge wavelengths are closely related to canopy chlorophyll content [55], and canopy chlorophyll content is 
strongly related to LAI [58,59], previous studies successfully predicted LAI by using chlorophyll-related SIs such as CIred-edge [10,53]. According to such results, another possible reason for the success of DSIR760-R739 for LAI prediction is the high sensitivity of reflectance values at red-edge wavelengths (739 $\mathrm{nm}$ in this study) to the canopy chlorophyll content.

The analyses revealed that NDVI, EVI, and OSAVI (normalized difference indexing) are in a nonlinear relationship with LAI (Figure $3 \mathrm{a}-\mathrm{c}$ ) and are less sensitive to changes in LAI at high LAI values (Figure 4). The main reason for the low sensitivity of these SIs could be their normalized-difference processing; this processing of the $\rho$ NIR and pred values makes the SIs insensitive to variations in the $\rho_{N I R}$ when $\rho_{\mathrm{NIR}} \gg \rho_{\mathrm{red}}[17]$. SIs that take normalized difference processing tend to be insensitive to changes in LAI at high LAI values. In contrast, the WDRVI, a linear transformation of the normalized difference of $\rho_{\text {NIR }}$ and $\rho_{\text {red, }}$ is more sensitive to changes in LAI at moderate to high LAI values (Figure 4). Thus, introducing a weight coefficient such as the WDRVI's " $\alpha$ " is a simple and efficient approach to enhance sensitivity to LAI under moderate to high LAI conditions. Although its sensitivity at high LAI values was slightly inferior to that of DSIR760-R739, the WDRVI is useful for LAI assessment.

We also confirmed the applicability of chlorophyll-related SIs (e.g., CIred-edge and CIgreen) at the leaf scale for LAI assessment (Figures 3e,f and 4). These results are consistent with a previous study [10,53]. When a reflectance value at $760 \mathrm{~nm}$ is used as the $\rho_{\text {NIR }}$ of $\mathrm{CI}_{\text {red-edge, the }} \mathrm{CI}_{\text {red-edge }}$ becomes an index similar to RSIR760-R730, which indicates higher predictive accuracy and sensitivity. Therefore, CIred-edge, computed by the red-edge and the shortest part of the NIR wave region, is more useful for LAI assessment than SIs that use the longer part of the NIR wave region. The CIred-edge has been successfully applied to LAI assessment of maize, soybeans [10], and wheat crops [53]. Thus, we believe that the CIred-edge is useful for LAI assessment regardless of crop type. Nevertheless, note that a high spectral resolution was required to observe optimal wavelengths because the optimal bandwidth of this SI was observed to be narrow, as shown in the RSI contour map (Figure $2 b$ ).

Among the SIs tested in this study, DSIR760-R739 was the most linearly and closely related SI to LAI and demonstrated the best performance for the ground-based dataset. The advantage demonstrated by DSI $760-\mathrm{R} 739$ was its higher sensitivity in detecting changes in LAI at moderate to high LAI values (3.0-5.5). The ground-based dataset was collected at multiple growth stages during the two-year experiment (Table 3). In spite of the clear differences in ground and canopy conditions, DSIR760-R739 could accurately predict the LAI.

In monitoring the crop nitrogen status of rice and wheat, Wang et al. [36] reported that the relatively wide bandwidths (36, 15, and $21 \mathrm{~nm}$ for 924, 703, and $423 \mathrm{~nm}$ wavelengths, respectively) in their three broad-band vegetation index are ideal for sensor design. However, our study found rapid decreases in predictive accuracy, especially for the $760 \mathrm{~nm}$ center wavelength. The permissible bandwidths for DSIR760-R739 determined by the optimal $1_{1.05}$ criterion were found to be $5 \mathrm{~nm}$ at both the $760 \mathrm{~nm}$ and 739 $\mathrm{nm}$ center wavelengths. The result of this study is consistent with previous studies showing that narrow-band SIs from hyperspectral remote sensing are suitable for monitoring crop growth (e.g., [33,60]). However, even though the bandwidths of DSIR760-R739 are wider (e.g., $15 \mathrm{~nm}$ for both wavelengths), the predictive accuracy of the model was still higher than existing SIs (Figure 5). Therefore, like the narrow-band DSIR760-R739, which is suitable for LAI assessment, the broad-band DSIR760-R739 may also prove to be useful for LAI assessment. 
Le Maire et al. [61] conducted a systematic study aimed at finding efficient hyperspectral indices for the estimation of forest sun leaf chlorophyll content, sun leaf mass per area, LAI, and leaf canopy biomass using radiative transfer models, canopy reflectance data, and Hyperion images. They found a reliable index that uses difference of reflectance value at 1725 and $970 \mathrm{~nm}$ (i.e., $\mathrm{R}_{1725}-\mathrm{R}_{970}$ ). In the spectral range that we tested, and in the form of normalized difference, they reported that the combination of NIR and blue reflectance is the most useful spectral region for LAI estimation. However, the results of the present study suggested that the combination of NIR and blue reflectance are not useful for LAI assessment of winter wheat. A possible reason for this significant difference is the difference in ranges in LAI values because le Maire et al. estimated LAI in ranges $>3.0$ in their study. Although this study was site-specific and did not include wavelengths longer than $1000 \mathrm{~nm}$, the ranges of LAI in the datasets were $0.3-5.5$, sufficiently broad to evaluate the predictive ability of SIs (Table 4). The DSIR760-R739 developed for the wide ranges of LAI values in this study would therefore be reliable for LAI assessment of wheat crops.

Similar to our study, some previous studies have reported that the first-derivative reflectance of red-edge wavelengths or SIs using red-edge wavelengths and wavelengths at 730-760 nm are closely related to the LAI of paddy rice [40], wheat [26,53], and pasture biomass [35]. Another study suggested that the first-derivative reflectance at $740 \mathrm{~nm}$ has high sensitivity to the difference in LAI of paddy rice at the panicle-formation stage [6]. The results of further studies investigating the spectral response of DSI $760-\mathrm{R} 739$ for LAI assessment of multiple crops or vegetation types would be interesting and significant to confirm the robustness of the DSIR760-R739 predictive model because of the differing spectral responses among crops [32,42,43]. For example, an analysis comparing wheat and paddy rice, which are the two major gramineous crops that have relatively similar canopy structures, would be very interesting and required to determine the suitability of DSIR760-R739 for remotely assessing LAI. In addition, since all the ground datasets in our study were pooled and then used for statistical analysis, this study could not clarify the applicability of DSIR760-R739 for determining differences in wheat varieties and fertilization. In the future, we will examine other fields with different wheat varieties and fertilizer management techniques by using a larger dataset with a wider range of LAI values.

\section{Conclusions}

To identify simple and accurate SIs for LAI assessment of winter wheat, this study evaluated the predictive ability and sensitivity of several SIs with respect to LAI assessment. Hyperspectral and ground data collected at the middle and late growing stages were used to identify useful SIs in the present study.

During the study, three new SIs (DSIR760-R739, RSIR760-R730, and NDSIR760-R730) were developed based on the empirical relationships between LAIs and SIs of all available two-waveband combinations from hyperspectral data. Of the 12 SIs that were tested, DSIR760-R739 was the most linearly and closely related to LAI and the most sensitive to changes in LAI at moderate to high LAI conditions. The permissible bandwidths for broad-band DSIR760-R739 were identified as $5 \mathrm{~nm}$ at both center wavelengths. The narrowband and broad-band DSI $760-\mathrm{R} 739$ could be used for LAI assessment with portable spectroradiometers, thus providing useful information for farmers to conduct improved site-specific crop management and sustainable agricultural decisions. 
Since all the ground datasets in our study were pooled and then used for statistical analysis, this study could not clarify the applicability of DSIR760-R739 for determining differences in wheat varieties and fertilization. In the future, we will examine other fields with different wheat varieties and fertilizer management techniques by using a larger dataset with a wider range of LAI values. In addition, we will also examine the response of the DSIR760-R739 for LAI assessments for multiple crops or vegetation types to confirm the robustness of the predictive model based on DSIR760-R739.

\section{Acknowledgments}

All data used in this study were collected when the first author was a graduate student at the River Basin Research Center, Gifu University. We are grateful to the members of this center for their encouragement. Comments from G. Takao, M. Takahashi, T. Nishizono, and T. Takahashi (FFPRI), and from anonymous reviewers served to greatly improve the early drafts of this manuscript. This study was partially supported by a grant from the Ministry of Education, Culture, Sports, Science and Technology, Japan ("Satellite Ecology", the 21st Century COE Program at Gifu University), and the Forestry and Forest Products Research Institute (FFPRI).

\section{Author Contributions}

Shinya Tanaka designed this study, collected field data, and performed all statistical analyses, with the co-authors providing mentorship throughout the study. Shinya Tanaka and Kensuke Kawamura jointly wrote the manuscript. Masayasu Maki collected the reflectance data on 10 April 2007 and helped interpretation of results. Yasunori Muramoto and Kazuaki Yoshida managed wheat growth. Tsuyoshi Akiyama conceived the present study. All authors have read and approved the final manuscript.

\section{Conflicts of Interest}

The authors declare no conflict of interest.

\section{References}

1. Dente, L.; Satalino, G.; Mattia, F.; Rinaldi, M. Assimilation of leaf area index derived from ASAR and MERIS data into CERES-Wheat model to map wheat yield. Remote Sens. Environ. 2008, 112, 1395-1407.

2. Pinter, P.J.; Hatfield, J.L.; Schepers, J.S.; Barnes, E.M.; Moran, M.S.; Daughtry, C.S.; Upchurch, D.R. Remote sensing for crop management. Photogramm. Eng. Remote Sens. 2003, 69, 647-664.

3. Baret, F.; Buis, S. Estimating canopy characteristics from remote sensing observations: Review of methods and associated problems. In Advances in Land Remote Sensing; Liang, S., Ed.; Springer: Dordrecht, The Netherlands, 2008; pp. 173-201.

4. Campbell, G.S.; Norman, J.M. The description and measurement of plant canopy structure. In Plant Canopies: Their Growth, Form and Function; Cambridge University Press: Cambridge, UK, 1989; pp. 1-10. 
5. Casa, R.; Varella, H.; Buis, S.; Guérif, M.; de Solan, B.; Baret, F. Forcing a wheat crop model with LAI data to access agronomic variables: Evaluation of the impact of model and LAI uncertainties and comparison with an empirical approach. Eur. J. Agron. 2012, 37, 1-10.

6. Inoue, Y.; Sakaiya, E.; Zhu, Y.; Takahashi, W. Diagnostic mapping of canopy nitrogen content in rice based on hyperspectral measurements. Remote Sens. Environ. 2012, 126, 210-221.

7. Moran, M.S.; Inoue, Y.; Barnes, E.M. Opportunities and limitations for image-based remote sensing in precision crop management. Remote Sens. Environ. 1997, 61, 319-346.

8. Shibayama, M.; Sakamoto, T.; Takada, E.; Inoue, A.; Morita, K.; Takahashi, W.; Kimura, A. Estimating paddy rice leaf area index with fixed point continuous observation of near infrared reflectance using a calibrated digital camera. Plant Prod. Sci. 2011, 14, 30-46.

9. Maki, M.; Homma, K. Empirical regression models for estimating multiyear leaf area index of rice from several vegetation indices at the field scale. Remote Sens. 2014, 6, 4764-4779.

10. Viña, A.; Gitelson, A.A.; Nguy-Robertson, A.L.; Peng, Y. Comparison of different vegetation indices for the remote assessment of green leaf area index of crops. Remote Sens. Environ. 2011, $115,3468-3478$.

11. Wu, J.; Wang, D.; Bauer, M.E. Assessing broadband vegetation indices and QuickBird data in estimating leaf area index of corn and potato canopies. Field Crops Res. 2007, 102, 33-42.

12. Rouse, J.W.; Haas, R.H.; Schell, J.A.; Deering, D.W. Monitoring vegetation systems in the Great Plains with ERTS. Third ERTS Symp. NASA SP-351 I 1973, 351, 309-317.

13. Huete, A.R. A soil-adjusted vegetation index (SAVI). Remote Sens. Environ. 1988, 25, 295-309.

14. Huete, A.; Didan, K.; Miura, T.; Rodriguez, E.P.; Gao, X.; Ferreira, L.G. Overview of the radiometric and biophysical performance of the MODIS vegetation indices. Remote Sens. Environ. 2002, 83, 195-213.

15. Qi, J.; Chehbouni, A.; Huete, A.R.; Kerr, Y.H.; Sorooshian, S. A modified soil adjusted vegetation index. Remote Sens. Environ. 1994, 48, 119-126.

16. Rondeaux, G.; Steven, M.; Baret, F. Optimization of soil-adjusted vegetation indices. Remote Sens. Environ. 1996, 55, 95-107.

17. Gitelson, A.A. Wide Dynamic Range Vegetation Index for remote quantification of biophysical characteristics of vegetation. J. Plant Physiol. 2004, 161, 165-173.

18. Gitelson, A.A.; Gritz, Y.; Merzlyak, M.N. Relationships between leaf chlorophyll content and spectral reflectance and algorithms for non-destructive chlorophyll assessment in higher plant leaves. J. Plant Physiol. 2003, 160, 271-282.

19. Chen, J.M.; Pavlic, G.; Brown, L.; Cihlar, J.; Leblanc, S.G.; White, H.P.; Hall, R.J.; Peddle, D.R.; King, D.J.; Trofymow, J.A.; et al. Derivation and validation of Canada-wide coarse-resolution leaf area index maps using high-resolution satellite imagery and ground measurements. Remote Sens. Environ. 2002, 80, 165-184.

20. Haboudane, D.; Miller, J.R.; Pattey, E.; Zarco-Tejada, P.J.; Strachan, I.B. Hyperspectral vegetation indices and novel algorithms for predicting green LAI of crop canopies: Modeling and validation in the context of precision agriculture. Remote Sens. Environ. 2004, 90, 337-352.

21. Potithep, S.; Nagai, S.; Nasahara, K.N.; Muraoka, H.; Suzuki, R. Two separate periods of the LAI-VIs relationships using in situ measurements in a deciduous broadleaf forest. Agric. For. Meteorol. 2013, 169, 148-155. 
22. Sakamoto, T.; Gitelson, A.A.; Nguy-Robertson, A.L.; Arkebauer, T.J.; Wardlow, B.D.; Suyker, A.E.; Verma, S.B.; Shibayama, M. An alternative method using digital cameras for continuous monitoring of crop status. Agric. For. Meteorol. 2012, 154-155, 113-126.

23. Shibayama, M.; Akiyama, T. Seasonal visible, near-infrared and mid-infrared spectra of rice canopies in relation to LAI and above-ground dry phytomass. Remote Sens. Environ. 1989, 27, 119-127.

24. Welles, J.M.; Cohen, S. Canopy structure measurement by gap fraction analysis using commercial instrumentation. J. Exp. Bot. 1996, 47, 1335-1342.

25. Ministry of Agriculture. Forestry and Fisheries of Japan (MAFF) Statistics of Agriculture, Forestry and Fisheries. Available online: http://www.maff.go.jp/j/tokei/kouhyou/sakumotu/ sakkyou_kome/pdf/syukaku_mugi_14.pdf (accessed on 14 November 2014).

26. Hansen, P.M.; Schjoerring, J.K. Reflectance measurement of canopy biomass and nitrogen status in wheat crops using normalized difference vegetation indices and partial least squares regression. Remote Sens. Environ. 2003, 86, 542-553.

27. Jin, X.; Diao, W.; Xiao, C.; Wang, F.; Chen, B.; Wang, K.; Li, S. Estimation of wheat agronomic parameters using new spectral indices. PLOS ONE 2013, 8, e72736.

28. Inoue, Y.; Iwasaki, K. Spectral estimation of radiation absorptance and leaf area index in corn canopies as affected by canopy architecture and growth stage. Jpn. J. Crop Sci. 1991, 60, $578-580$.

29. Li, F.; Miao, Y.; Hennig, S.D.; Gnyp, M.L.; Chen, X.; Jia, L.; Bareth, G. Evaluating hyperspectral vegetation indices for estimating nitrogen concentration of winter wheat at different growth stages. Precis. Agric. 2010, 11, 335-357.

30. Smith, A.M.; Bourgeois, G.; Teillet, P.M.; Freemantle, J.; Nadeau, C. A comparison of NDVI and MTVI2 for estimating LAI using CHRIS imagery: A case study in wheat. Can. J. Remote Sens. 2008, 34, 539-548.

31. Thenkabail, P.S.; Lyon, J.G.; Huete, A. Hyperspectral Remote Sensing of Vegetation; CRC Press: Boca Raton, FL, USA, 2012.

32. Mariotto, I.; Thenkabail, P.S.; Huete, A.; Slonecker, E.T.; Platonov, A. Hyperspectral versus multispectral crop-productivity modeling and type discrimination for the HyspIRI mission. Remote Sens. Environ. 2013, 139, 291-305.

33. Thenkabail, P.S.; Gumma, M.K.; Teluguntla, P.; Mohammed, I.A. Hyperspectral remote sensing of vegetation and agricultural crops. Photogramm. Eng. Remote Sens. 2014, 80, 697-709.

34. Delegido, J.; Verrelst, J.; Meza, C.M.; Rivera, J.P.; Alonso, L.; Moreno, J. A red-edge spectral index for remote sensing estimation of green LAI over agroecosystems. Eur. J. Agron. 2013, 46, $42-52$.

35. Mutanga, O.; Skidmore, A.K. Narrow band vegetation indices overcome the saturation problem in biomass estimation. Int. J. Remote Sens. 2004, 25, 3999-4014.

36. Wang, W.; Yao, X.; Yao, X.; Tian, Y.; Liu, X.; Ni, J.; Cao, W.; Zhu, Y. Estimating leaf nitrogen concentration with three-band vegetation indices in rice and wheat. Field Crops Res. 2012, 129, 90-98. 
37. Kanemoto, M.; Tanaka, S.; Kawamura, K.; Matsufuru, H.; Yoshida, K.; Akiyama, T. Wavelength selection for estimating biomass, LAI, and leaf nitrogen concentration in winter wheat of Gifu prefecture using in situ hyperspectral data. J. Jpn. Agric. Syst. Soc. 2008, 24, 43-56.

38. Muramoto, Y.; Yoshida, K. A study of production technique for high-quality wheat grains using controlled-release coated urea fertilizer. Bull. Gifu Prefect. Agric. Technol. Cent. 2010, 10, 1-9.

39. Tanaka, S.; Goto, S.; Maki, M.; Akiyama, T.; Muramoto, Y.; Yoshida, K. Estimation of leaf chlorophyll concentration in winter wheat before maturing stage by a newly developed vegetation index-rbNDVI. J. Jpn. Agric. Syst. Soc. 2007, 23, 297-303.

40. Evri, M.; Akiyama, T.; Kawamura, K. Optimal visible and near-infrared waveband used in hyperspectral indices to predict crop variables of rice. J. Jpn. Agric. Syst. Soc. 2008, 24, 19-29.

41. Inoue, Y.; Miah, G.; Sakaiya, E.; Nakano, K.; Kawamura, K. NDSI map and IPLS using hyperspectral data for assessment of plant and ecosystem variables. J. Remote Sens. Soc. Jpn. 2008, 28, 317-330.

42. Thenkabail, P.S.; Smith, R.B.; De Pauw, E. Hyperspectral vegetation indices and their relationships with agricultural crop characteristics. Remote Sens. Environ. 2000, 71, 158-182.

43. Marshall, M.; Thenkabail, P. Biomass modeling of four leading world crops using hyperspectral narrowbands in support pf HyspIRI mission. Photogramm. Eng. Remote Sens. 2014, 80, 757-772.

44. Ciganda, V.; Gitelson, A.; Schepers, J. Non-destructive determination of maize leaf and canopy chlorophyll content. J. Plant Physiol. 2009, 166, 157-167.

45. Akaike, H. A new look at the statistical model identification. IEEE Trans. Autom. Control 1974, 19, 716-723.

46. Kawamura, K.; Watanabe, N.; Sakanoue, S.; Lee, H.-J.; Inoue, Y.; Odagawa, S. Testing genetic algorithm as a tool to select relevant wavebands from field hyperspectral data for estimating pasture mass and quality in a mixed sown pasture using partial least squares regression. Grassl. Sci. 2010, 56, 205-216.

47. Mutanga, O.; Skidmore, A.K.; Prins, H.H. T. Predicting in situ pasture quality in the Kruger National Park, South Africa, using continuum-removed absorption features. Remote Sens. Environ. 2004, 89, 393-408.

48. Gitelson, A.A. Remote estimation of crop fractional vegetation cover: The use of noise equivalent as an indicator of performance of vegetation indices. Int. J. Remote Sens. 2013, 34, 6054-6066.

49. Viña, A.; Gitelson, A.A. New developments in the remote estimation of the fraction of absorbed photosynthetically active radiation in crops. Geophys. Res. Lett. 2005, 32, L17403.

50. R Development Core Team. R: A Language and Environment for Statistical Computing; $\mathrm{R}$ Foundation for Statistical Computing: Vienna, Austria, 2012.

51. McRoberts, R.E.; Nelson, M.D.; Wendt, D.G. Stratified estimation of forest area using satellite imagery, inventory data, and the $k$-Nearest Neighbors technique. Remote Sens. Environ. 2002, 82, 457-468.

52. Herrmann, I.; Pimstein, A.; Karnieli, A.; Cohen, Y.; Alchanatis, V.; Bonfil, D.J. LAI assessment of wheat and potato crops by VEN $\mu \mathrm{S}$ and Sentinel-2 bands. Remote Sens. Environ. 2011, 115, 2141-2151. 
53. Li, X.; Zhang, Y.; Bao, Y.; Luo, J.; Jin, X.; Xu, X.; Song, X.; Yang, G. Exploring the best hyperspectral features for LAI estimation using partial least squares regression. Remote Sens. 2014, 6, 6221-6241.

54. Schlemmer, M.; Gitelson, A.; Schepers, J.; Ferguson, R.; Peng, Y.; Shanahan, J.; Rundquist, D. Remote estimation of nitrogen and chlorophyll contents in maize at leaf and canopy levels. Int. J. Appl. Earth Obs. Geoinf. 2013, 25, 47-54.

55. Filella, I.; Serrano, L.; Serra, J.; Peñuelas, J. Evaluating wheat nitrogen status with canopy reflectance indices and discriminant analysis. Crop Sci. 1995, 35, 1400-1405.

56. Filella, I.; Penuelas, J. The red edge position and shape as indicators of plant chlorophyll content, biomass and hydric status. Int. J. Remote Sens. 1994, 15, 1459-1470.

57. Daughtry, C.S. T.; Walthall, C.L. Spectral discrimination of Cannabis sativa L. leaves and canopies. Remote Sens. Environ. 1998, 64, 192-201.

58. Peng, Y.; Gitelson, A.A.; Keydan, G.; Rundquist, D.C.; Moses, W. Remote estimation of gross primary production in maize and support for a new paradigm based on total crop chlorophyll content. Remote Sens. Environ. 2011, 115, 978-989.

59. Gitelson, A.A.; Peng, Y.; Arkebauer, T.J.; Schepers, J. Relationships between gross primary production, green LAI, and canopy chlorophyll content in maize: Implications for remote sensing of primary production. Remote Sens. Environ. 2014, 144, 65-72.

60. Thenkabail, P.S.; Smith, R.B.; de Pauw, E. Evaluation of narrowband and broadband vegetation indices for determining optimal hyperspectral wavebands for agricultural crop characterization. Photogramm. Eng. Remote Sens. 2002, 68, 607-621.

61. Le Maire, G.; François, C.; Soudani, K.; Berveiller, D.; Pontailler, J.-Y.; Bréda, N.; Genet, H.; Davi, H.; Dufrêne, E. Calibration and validation of hyperspectral indices for the estimation of broadleaved forest leaf chlorophyll content, leaf mass per area, leaf area index and leaf canopy biomass. Remote Sens. Environ. 2008, 112, 3846-3864.

(C) 2015 by the authors; licensee MDPI, Basel, Switzerland. This article is an open access article distributed under the terms and conditions of the Creative Commons Attribution license (http://creativecommons.org/licenses/by/4.0/). 